\title{
Migración internacional, remesas y cambios en la estructura territorial de la economía en el municipio de Cerritos, San Luis Potosí, México ${ }^{1}$
}

\author{
Areli Cuevas Ochoa² y Valente Vázquez Solís²
}

\begin{abstract}
RESUMEN
La migración de la población mexicana hacia Estados Unidos de América es un proceso social que al inicio del siglo XXI adquiere connotaciones novedosas. Parte de su importancia reside en que se ha convertido en la segunda fuente de ingresos nacionales, solo después de los recursos obtenidos por concepto de la exportación de petróleo. Numerosos estudios han examinado las causas y efectos asociados con tales movimientos, como la pobreza, la falta de empleo, los conflictos políticos, la educación, la diferencia en el nivel de bienestar, el poder adquisitivo y la disparidad de salarios entre ambos países, por citar algunos. Sin embargo, existen otras manifestaciones de singular importancia que acompañan a la migración, tales como los cambios generados en la organización y la estructura de los lugares en donde se invierten o gastan las remesas. El estado de San Luis Potosí se distingue como una de las entidades federativas que evidencian una intensidad notable, tanto en los flujos migratorios hacia aquel país como en la captación de remesas. Este trabajo revela los impactos de la migración motivados por el envío de remesas en la estructura territorial de la economía en el municipio de Cerritos, uno de los que, en el contexto estatal, presenta mayores cambios en la dinámica económica en su territorio a consecuencia de tal proceso.
\end{abstract}

Palabras clave: Migración, remesas, estructura territorial, Cerritos, San Luis Potosí.

\begin{abstract}
The migration of Mexicans to the United States of America is an ancient process, but it is now having new connotation. One the most important aspects of this international migration is the fact that it has become the second source of national income, second to resources obtained from oil. Numerous investigations have examined the causes and effects associated to the migrations such as poverty, unemployment, political conflicts, education, and the salary differences between the two nations. However, there are other manifestations that accompany this migration, such as changes generated in the organization and structure of places where money is invested. San Luis Potosi can be distinguished has the place that shows an intense migratory flow towards the United States of America and that attracts remittances. This work reveals the impacts of migration motivated by remittances on the territorial structure of the economy of Cerritos, which presents the highest numbers of changes in economic dynamics on its territory due to the process of migration.
\end{abstract}

Key words: Migration, money remittance, territorial structure, Cerritos, San Luis Potosi.

Artículo recibido el 19 de noviembre de 2008 y aceptado el 2 de marzo de 2009.

\footnotetext{
2 Licenciatura en Geografía, Universidad Autónoma de San Luis Potosí (México). E-mail: arley_ 84aj@hotmail.com; vazquezsv@uaslp.mx
} 
La migración de mexicanos hacia Estados Unidos adquiere singular importancia en años recientes, dado el nivel de participación que ha tenido para la economía nacional en lo que se refiere a la generación de ingresos. Desde el año 2005 a la fecha, el dinero procedente de las remesas de connacionales que habitan en Estados Unidos es el sostén de millones de personas en México; esta situación deriva en el incremento del flujo monetario y de bienes materiales hacia zonas, con frecuencia, económicamente deprimidas.

Bajo estas circunstancias, la migración de la población se acompaña por una serie de cambios conductuales y organizativos, tanto para quien se desplaza como para la familia nuclear, y que se han detallado ampliamente en estudios de corte antropológico, sociológico y psicológico. No obstante, es importante señalar que tales cambios se expresan también en un nuevo orden microrregional producto de la forma en la que se gastan o invierten en el lugar de origen los recursos económicos y materiales provenientes de las remesas obtenidas por quienes trabajan en aquel país, evidenciados en la habilitación de infraestructura, mejora en la disponibilidad de servicios en las viviendas y obras orientadas a mejorar las condiciones de vida y trabajo en las localidades y regiones receptoras.

Esta situación se presenta en el municipio de Cerritos, San Luis Potosí, donde el dinero proveniente del envío de remesas que efectúan los emigrantes que residen en Estados Unidos ha generado un impacto diferencial en la estructura socioeconómica del territorio expulsor y que se manifiesta, entre otras formas, mediante la reducción de fuerza de trabajo disponible y la mayor presencia de ancianos, niños y mujeres. A cambio, las remesas movilizadas por los trabajadores migrantes generan condiciones que impactan en el bienestar familiar, las costumbres locales, los servicios municipales y la dinámica comercial de los residentes locales.

\section{Consideraciones teóricas elementales}

Numerosas investigaciones históricas y contemporáneas se han interesado por la migración, tanto por los procesos que le atañen directamente, como por las causas que se vinculan a ella. Aunque no es afán de este trabajo hacer un acopio detallado de las investigaciones que sobre migración internacional se han desarrollado, tal alusión ejemplifica la variedad de estudios y la necesidad de examinar un proceso que si bien no es emergente, la creciente complejidad que evidencia la migración, la ubica como una temática de necesario interés para las ciencias sociales. Así, si bien la migración es un proceso complejo que ha sido objeto de múltiples abordajes por distintas disciplinas (Veleda, 2001), es necesario señalar que ninguna teoría, hasta la fecha, puede explicar los procesos y condiciones asociados a la migración de una forma totalizadora que incluya todas sus variantes y manifestaciones. Aun con ello, todos los aportes teóricos referentes a la migración cobran gran importancia y relevancia para comprender los procesos registrados en la actualidad.

A este respecto, la migración ha sido valorada de forma científica desde finales del siglo XIX a partir de modelos de repulsión-atracción o push and pull, sustentados en estadísticas que tenían la intención de mesurar la manera en la que se redistribuye la población en el territorio, motivada por factores propios del sitio de origen, tales como las leyes opresivas, los altos impuestos, un clima poco atractivo y las condiciones sociales desagradables (Castles y Miller, 2004).

Otras teorías que explican la migración a nivel internacional se sustentan en preceptos macroeconómicos provenientes de la economía clásica y examinan las diferencias salariales entre los países que reflejan desigualdad en los niveles de ingresos y bienestar (Durand y Massey, 2003); o bien adicionan variantes como la new economics of labor migration (nueva teoría de la migración) que considera, además de las causas y consecuencias de la emigración en lugares de origen, la función que desempeña la familia en la decisión de migrar para algunos miembros, la dinámica de las remesas y las complejas interdependencias generadas entre los emigrantes (Arango, 2003; Durand y Massey, 2003; Castles y Miller, 2004). 
En los últimos años han adquirido relevancia algunas vertientes de conocimiento que examinan a la migración a partir de las condiciones laborales y culturales existentes en los espacios geográficos receptores de migrantes, asociados a la demanda de fuerza de trabajo externa (Piore, 1979); en tanto, algunos autores como Portes y Sassen, en 1989, observan a la migración como resultado de la penetración de la economía capitalista de mercado en los países menos desarrollados y donde la generación de desequilibrios en los mercados locales crea población móvil proclive a migrar hacia los centros industrializados (Rocha, 2003).

Por su parte, la teoría de la migración en la economía internacional actual distingue a la migración económica y la migración de trabajo temporal como categorías analíticas del fenómeno. La primera se da por los movimientos para la subsistencia y la mejora socioeconómica. En tanto, la segunda hace énfasis en las personas que emigran por un periodo limitado, bien para obtener un beneficio personal o para enviar remesas a sus lugares de origen (Barros, 2005).

Algunas perspectivas antropológicas señalan la importancia de referir los vínculos interpersonales que enlaza a emigrantes con viejos emigrantes en su área de origen y de destino a través de los lazos de parentesco, amistad y comunidad de origen compartida (Arango, 2003). De esta manera se otorga un significado especial a las cadenas migratorias como factor clave en la decisión por emigrar y en la selección del sitio de destino. En este contexto, tales nociones cognoscitivas contribuyen a entender la continuidad de los flujos migratorios a pesar de la desaparición o cambio en los factores que existieron al inicio, así como la valoración de la decisión individual y la conciencia colectiva (Giusti, 2005; Lacomba, 2001).

En síntesis, aún hasta el decenio de los ochenta del siglo XX, la mayoría de los estudios referidos a la migración a partir de los postulados teóricos descritos con anterioridad, se circunscribían a dos corrientes epistemológicas principales: una que parte del análisis económico-marxista para enfatizar los efectos estructurales asociados con la migración en el mundo; y la segunda que centra su objeto de estudio en el individuo que la lleva a cabo y subsume los efectos estructurales del proceso; entre estos destacan los enfoques orientados al análisis del comportamiento, la percepción y la racionalidad (Veleda, 2001). A partir de los años noventa del siglo XX los científicos sociales, en especial los geógrafos, priorizan el estudio de los desplazamientos humanos a través de una perspectiva concreta: la consideración de la acción del migrante, pero dentro de un contexto estructural, sea cultural, espacial y temporal, perspectiva bajo la cual se orienta el presente estudio.

\section{Migración de México y San Luis Potosí hacia Estados Unidos}

\section{Antecedentes históricos}

El éxodo de migrantes mexicanos hacia Estados Unidos ejemplifica uno de los factores que inciden no solo en la conformación étnica y cultural de algunas sociedades latinoamericanas, sino la dinámica poblacional vinculada con la movilización desde el sur hacia los polos de desarrollo localizados en América del Norte. Este proceso se identifica con mayor precisión desde finales del siglo XIX y se desarrolló con plenitud durante el siglo XX, pero en los últimos años ha cobrado un dinamismo sin precedentes, situación asociada a la consolidación de una modalidad de integración económica profundamente asimétrica entre los dos países (Delgado y Mañán, 2005).

Desde el decenio de 1890, Estados Unidos buscó la incorporación de trabajadores mexicanos a diversos sectores de la producción en repetidas ocasiones. Sin embargo, estos intentos prosperaron solo cuando a la demanda estadounidense se le unieron acontecimientos ocurridos en México, que facilitaron, condicionaron e incluso obligaron la movilización de personas, tales como la Revolución Mexicana, que durante su desarrollo entre 1910 y 1921, y con posteridad la revuelta cristera (Durand, 1991), derivaron en inestabilidad social y económica que motivaron la migración de un sector de la población hacia Estados Unidos, algunos para mejorar sus condiciones económicas y 
otros para evadir los peligros ocasionados por la revuelta (Verduzco, 2000).

Desde entonces, la dinámica migratoria de México-Estados Unidos se ha intensificado al grado de repercutir en el ámbito político, económico y social, con la incorporación de nuevos sitios de origen y recepción de personas. Al respecto, la migración entre estos dos países distingue cuatro grandes etapas temporales que a continuación se sintetizan:

1) Periodo del enganche. Una vez que se inició la Revolución Mexicana y, poco después, cuando Estados Unidos tuvo déficit de fuerza de trabajo para el desarrollo de actividades primarias tras su ingreso a la Primera Guerra Mundial, se ideó un sistema de contratación de mano de obra privada y semiforzada denominada enganche. Esta etapa se sitúa entre 1900 y 1920 (González, 2001).

En el caso de San Luis Potosí, la población de la capital del estado, Matehuala, Venado, Cedral y otras localidades que se ubicaban a lo largo de la ruta del ferrocarril que unía a la ciudad de México con Laredo y El Paso, Texas, evidenciaron un éxodo hacia estos asentamientos fronterizos, principalmente hacia el estado de California (Alanis, 2001; Montoya, 2006), aunque estos flujos de personas se habían iniciado desde 1882 a consecuencia de la baja productividad agrícola, actividad practicada de forma preponderante por la población de esa región del Altiplano Potosino (Monroy, 2001).

2) Periodo del retorno masivo. Las crisis económicas recurrentes en Estados Unidos entre 1920 y 1941 motivaron el retorno de miles de mexicanos que en los años previos se trasladaron hacia aquel país (Monroy, 2001). A lo anterior se agregaron las deportaciones de muchos connacionales más, que el gobierno norteamericano justificó debido a que la inestabilidad económica generó un déficit de empleo con respecto a la fuerza de trabajo disponible. En ese momento los mexicanos deportados tuvieron dificultades para reintegrarse a la vida económica nacional (Durand, 1991).
Durante ese periodo el área industrial de Chicago, Gary y Detroit eran el destino de numerosos migrantes potosinos y en particular del municipio de Cerritos que se empleaban en las compañías ferroviarias del estado que ofrecían la oportunidad de trabajar en el tendido de rieles, al tiempo que trasportaron a cientos de personas para mantenimiento y reparación de las vías en el noreste de Estados Unidos (Montoya, 1997). Otras actividades en las que laboraban de forma complementaria eran la agricultura, la minería, la industria y las empacadoras, donde también laboraban migrantes procedentes de los municipios de Guadalcázar, San Nicolás Tolentino y Villa de Arista (Monroy, 2001).

3) Periodo bracero. Comenzó en 1942 debido a la necesidad de Estados Unidos por contar con trabajadores cuando este país inició su participación en la Segunda Guerra Mundial (Fernández, 2005). Este periodo se tipifica por la migración preferente de carácter temporal porque los emigrantes enganchados en el programa, varones en su mayoría, regresaron a sus hogares una vez terminado el contrato. Estos movimientos involucraron el traslado de mexicanos hacia aquel país para efectuar labores agrícolas y ganaderas en los campos de algodón y azúcar en Arizona, Nuevo México, Texas y California.

Además de los anteriores, los trabajadores potosinos se desplazaron hacia Colorado, Minnesota, Loussiana, Indiana, Dakota del Sur y Arkansas, de donde procedía población originaria de los municipios de Cerritos, Charcas, Villa de Ramos, Cerro de San Pedro, San Luis Potosí, San Nicolás Tolentino y Zaragoza, entre otros (González, 2001; Montoya, 2006). De manera paralela se instaló infraestructura para promover el desplazamiento de personas con la intención de trabajar en Estados Unidos. Así también, existían oficinas de contrataciones durante el programa bracero agrícola; una de ellas se situó en la ciudad de San Luis Potosí, lo que ocasionó grandes flujos de personas en busca de un contrato de trabajo en Estados Unidos (Monroy, 2001). 
4) Periodo de los indocumentados. Poco después de la conclusión del Programa Bracero, en 1964, el gobierno de Estados Unidos decidió poner fin a este tratado y optó por controlar el ingreso de migrantes con algunas medidas adicionales, tales como la legalización de un sector de la población trabajadora, la institucionalización de la frontera para el impedimento del paso y limitar el libre tránsito y la deportación sistemática de los trabajadores migrantes que no tuviesen sus documentos en regla. A partir de entonces, la emigración ilegal o indocumentada adquirió mayor relevancia para un sector importante de personas y aconteció entre 1965 y 1986 (Durand y Massey, 2003). Lo anterior no significa que hasta entonces fuera inexistente la migración ilegal, sino que a partir de ese año este tipo de emigrantes constituye el principal componente de esta modalidad de movimientos internacionales (Pérez, 2001).

\section{Dinámica contemporánea}

A finales de 1994, la crisis económica liberó millones de trabajadores agrícolas del campo mexicano (Verduzco, 2001), situación acompañada por las políticas neoliberales y el Tratado de Libre Comercio firmado ese año entre México, Estados Unidos y Canadá, que desprotegieron el sector tradicional de la agricultura en el país, por lo que los campesinos se vieron forzados a abandonar sus tierras y emigrar a los centros urbanos nacionales, o bien al extranjero (Aragonés et al., 2006). En este contexto, los patrones migratorios han evolucionando $y$ sumado a los desplazamientos una lista de nuevos actores además de los hombres, de tal forma que a estos contingentes se han incorporado mujeres, niños y familias.

En los últimos veinte años se han observado dos modalidades migratorias principales: por un lado se observan los movimientos temporales de ida y vuelta -circulares$y$, por otro, los efectuados por las personas que tienden a establecer una residencia permanente en Estados Unidos. Los grandes contingentes de fuerza de trabajo provienen principalmente de Zacatecas, San Luis Potosí, Guanajuato, Michoacán, Jalisco, Colima, Aguascalientes y Nayarit (Durand, 1991), a los que se han sumado los de población indígena de algunas de las entidades federativas con mayor grado de marginación socioeconómica del país, como es el caso de Puebla y Oaxaca (Herrera y Macías, 1997).

Durante el siglo recién concluido, la población de migrantes mexicanos residentes en Estados Unidos registró un incremento importante. Se estima que en 1900, alrededor de 100 mil personas nacidas en México residieron en la Unión Americana. Esta cifra se incrementó, lenta pero progresivamente hasta 1970, cuando alcanzó un número cercano a 800 mil personas. Diez años después el número de mexicanos residentes en Estados Unidos superaba los dos millones de personas; a partir de entonces el volumen se duplicó cada decenio, de tal forma que en 1990 el volumen de población nacional que habita en Estados Unidos ascendió a 4,4 millones y para el año 2000 alcanzó los 8,8 millones de personas (Zúñiga et al., 2005).

En el caso de San Luis Potosí, la Encuesta Nacional de Dinámica Demográfica, 19921997 (ENADID) indica que esta entidad federativa se ha posicionado como una de las principales expulsoras de población hacia Estados Unidos y supera incluso a Michoacán y Jalisco, estados con una notable tradición emigratoria. En el contexto estatal, y no obstante que las zonas Centro y Altiplano fueron las más impactadas por el proceso migratorio en sus inicios, en la actualidad se percibe con mayor intensidad en la zona Media, a la que pertenece el municipio de Cerritos.

\section{El impacto de las remesas}

En otro contexto, la migración entre México y Estados Unidos ha sido cuantiosa y cambiante (Durand, 1994), ello ha significado, a lo largo de su ya centenaria historia, una importante inyección de recursos monetarios que han desempeñado una función central en el sostenimiento de millones de familias en el campo y la ciudad, sobre todo en aquellas regiones y entidades donde la cantidad absoluta o proporción de emigrantes es mayor (Rodríguez, 2007).

Los estudios que versan sobre las remesas que envían los residentes mexicanos que 
laboran en Estados Unidos no son recientes, pero en gran medida han surgido trabajos de diferentes perspectivas académicas concernientes al tema. En este sentido, en la literatura producida durante el último cuarto del siglo XX, como las investigaciones realizadas por Russell en 1986 y 1992, Ahulburg en 1991, Lozano en 1991 y Taylor et al. en 1996, se advierte el predominio de una visión pesimista respecto al uso e impacto de las remesas en los países de origen de los emigrantes (Lozano, 2000). En general, los resultados de tales trabajos sostienen que estos recursos se emplean principalmente en la manutención de la familia y solo una pequeña parte se destina para inversiones productivas.

Otros estudios efectuados por Durand, Parrado y Massey en 1996, Waller en 1998, Zárate en 1998, Diego en 1998, Alarcón en 2000, Serrano en 2000, Lowell y de la Garza en 2000, afirman que las remesas no se refieren exclusivamente a la formación de empresas, sino también a las inversiones en capital humano, efectuadas a través de la educación y la salud; en particular, las remesas familiares son esenciales en mayor medida para la alimentación, el pago de servicios de agua y electricidad, salud, vestido, y también para la compra de inmuebles como terrenos, la restauración o construcción de vivienda, entre otros (Lozano, 2000).

Con base en lo anterior, este trabajo valora la necesidad de realizar un análisis integral de los impactos socioeconómicos y territoriales generados por las remesas ${ }^{3}$ par-

\footnotetext{
3 Se emplea la connotación de remesa para designar al dinero, objeto o material de cualquier índole que envían los emigrantes, ya sea de carácter particular-individual o colectivo. Las remesas de carácter particular son el dinero recibido de manera directa por un hogar y se les denomina remesas monetarias de carácter particular o familiar, y cuando el dinero es enviado para el beneficio de la comunidad del emigrante, se les considera remesas monetarias de carácter colectivo. Por otro lado, cuando los envíos se efectúan en especies se les conoce como remesas no monetarias y según el destino que tenga se le nombra como remesa no monetaria de carácter particular o colectivo. La primera categoría de este tipo de remesas incluye ropa, calzado, electrodomésticos, por ejemplo; y en la segunda, además de los materiales anteriores
}

ticulares y colectivas, monetarias y no monetarias obtenidas por los migrantes del municipio de Cerritos que residen en la Unión Americana.

En particular, las remesas colectivas han adquirido gran importancia en los últimos años, ya que sus impactos positivos en las sociedades beneficiadas se han incrementa$\mathrm{do}^{4}$. Aunque en muchos casos no son perceptibles, eso ocurre también con las remesas no monetarias de carácter familiar o particular. Por eso se estima pertinente analizar los impactos que ocasiona el envío de remesas familiares y colectivas para entender la dinámica socioeconómica-territorial de Cerritos, un territorio altamente influenciado por la migración y el consiguiente envío de remesas.

\section{El contexto del territorio examinado}

\section{Cambios generados en la orientación y la estructura socioeconómica}

Por su ubicación geográfica, el municipio de Cerritos reúne condiciones particulares que lo distinguen en el contexto estatal. Se localiza en la faja tropical de América del Norte en los $22^{\circ} 26^{\prime}$ latitud Norte y $100^{\circ}$ $16^{\prime} 25^{\prime \prime}$ longitud Oeste, a una altura promedio de 1.153 m.s.n.m. Está enclavado en la porción occidental de la microrregión media

se incluyen sillas de ruedas, despensas, ambulancias, entre otras, para dar cumplimiento con un compromiso adquirido con la comunidad o municipio.

4 A diferencia de las remesas particulares, las remesas colectivas son constituidas por ciertas asociaciones de emigrantes pertenecientes al lugar de origen al que son enviadas. Las asociaciones vinculadas al pueblo de origen son organizaciones de base creadas por emigrantes mexicanos en los Estados Unidos. Estas asociaciones se originan a partir de redes sociales que emigrantes, provenientes del mismo pueblo o aldea en México, han establecido en la comunidad estadounidense donde ahora radican. Miembros de estas asociaciones, conocidas comúnmente como clubes de oriundos, buscan promover el bienestar de sus pueblos tanto de origen como de residencia, y reúnen dinero para apoyar obras públicas y proyectos sociales como: la donación de ambulancias y construcción de clínicas, entre otros apoyos que sirven para el bienestar de la sociedad a la que van destinados. 
del estado de San Luis Potosí. Representa tan solo el $1,5 \%$ de la superficie total del estado y colinda, al norte, con el municipio de Guadalcázar, al este con el municipio de Ciudad del Maíz, al oeste con los municipios de Armadillo de los Infante y Villa Hidalgo y al sur con el municipio de Villa Juárez.

Por las cualidades productivas y la orientación sectorial del territorio en donde se encuentra, Cerritos apoyó su economía en el comercio y servicios que se concentraban en la cabecera municipal, en tanto la agricultura de subsistencia y comercial en pequeña escala se practicaron en las comunidades dispersas del interior, aún hasta el último decenio del siglo XX. Sin embargo, las sequías recurrentes derivadas de la ausencia de lluvia durante tiempo prolongado, incrementaron el nivel de incertidumbre para efectuarlas. Aunque esto no era una situación nueva por sí sola, la falta de empleo y oportunidades de mejoramiento para la población local, los salarios bajos y la motivación de los residentes por reunirse con la familia que ya residía en Estados Unidos desde hace tiempo, dieron origen al incremento de los flujos migratorios hacia aquel país.

A partir de entonces y aun cuando las oportunidades laborales se diversificaron con la instalación de pequeñas y una gran industria en las inmediaciones de Cerritos, la dinámica migratoria legal e ilegal se ha intensificado constante e inexorablemente, pues a los contingentes de varones en edad productiva, se han incorporado los de mujeres, niños y familias completas que por diversos motivos abandonan el sitio de origen para trasladarse a Estados Unidos. Evidencia de lo anterior es que de los 25.000 habitantes registrados con nacimiento en ese municipio para el año 2000, 10.000 viven principalmente en las ciudades de Chicago, Houston y Los Ángeles, así como una minoría que habita en Canadá (Alanís, 2005).

Pero al tiempo que se modifican la estructura y composición de estos flujos, también cambian los destinos preferenciales, de tal forma que California, estado de la Unión Americana que acogió grandes volúmenes de migrantes en decenios pasados, ha deja- do de tener tal distinción. Hoy en día, junto con otros destinos secundarios, Texas e Illinois, recibieron un volumen creciente de personas entre 1992 y 2007, que los ubicó como los destinos más concurridos por migrantes mexicanos hacia aquella nación (Alanís, 2005).

Entre los principales impactos que se pueden identificar en el territorio analizado se encuentran:

\section{Negativos}

a) Una tasa de crecimiento poblacional negativa entre 1990 y 2005, cuya cifra descendió de 21.380 a 20.425 habitantes. De todo el municipio, las localidades de Labor de San Diego, El Tepozán, Mezquites Chicos, El Tepetate, Tanquito de Banda son actualmente pequeños, poblados por niños y ancianos principalmente.

b) Carencia de fuerza de trabajo masculina en las actividades productivas.

c) Descuido de viviendas construidas con dinero procedente de remesas.

d) Reducción de la matrícula escolar.

e) Desintegración familiar derivada de la migración del jefe de familia a la Unión Americana (Villegas, 2005).

\section{Positivos}

a) Incremento en el flujo de recursos económicos, situación que ha dinamizado a la economía local y microrregional, entre las que se encuentra la aceleración de la industria de la construcción, especialmente de vivienda tipo americano ${ }^{5}$.

\footnotetext{
5 La vivienda tipo americano es aquella que se asemeja a los estilos arquitectónicos originales de construcciones que hay en los Estados Unidos de América y que son copiados por los migrantes para hacer una similar en el municipio; esas viviendas se identifican por ser construcciones bien distribuidas, con arcos, cúpulas, o diseños muy llamativos, ventanas grandes y corredizas al exterior e interior de la vivienda, así como de color casi siempre Ilamativo. El interior de estas viviendas trata de ser lo más elegante que se pueda, con cocinas grandes, salones de música, estudio de oficina y música, vista arriba (crown), fachadas grandes en las terrazas, buzones, portones eléctricos y pasto en la parte frontal y trasera.
} 
b) Incremento en los empleos disponibles en la industria de la construcción en el municipio.

c) Incremento de la actividad comercial de productos de consumo inmediato.

A continuación se valora la incidencia territorial de las remesas enviadas por los migrantes y destinadas al gasto e inversión en Cerritos.

\section{Metodología de estudio}

Los resultados que sustentan la presente investigación se obtuvieron del trabajo de campo efectuado en el municipio de Cerritos. Este se llevó a cabo en las comunidades de El Tepozán, Ojo de Agua, San Pedro de los Hernández, Joya de Luna, Mezquites Grandes y Mezquites Chicos, El Tepetate, La Biznaga, La Rinconada, Tanquito de Banda, El Zamandoque y en la cabecera municipal. Cabe destacar que se visitaron las comunidades que, por la magnitud de los flujos económicos recibidos, cuentan con mayor apoyo de las remesas individuales y colectivas.

Por el perfil que caracteriza a los emigrantes de este lugar, se aplicaron 130 entrevistas semiestructuradas a una mayoría de varones cuyas edades oscilan entre 20 y 40 años, y que reside, temporal o definitivamente, en estados de la Unión Americana, tales como Texas, California, Illinois, Georgia, Carolina del Norte, Oklahoma, Ohio, Florida, Arkansas, Indiana y Tennessee, principalmente (Figura $\mathrm{N}^{\circ} 1$ ).

Con el objetivo de identificar una perspectiva integral de la dinámica del envío de remesas por parte de los migrantes, también se aplicaron 130 entrevistas en hogares receptores de remesas ${ }^{6}$, que no necesariamen-

6 El trabajo se efectuó entre los meses de marzo y julio de 2007. En particular se aprovechó sobre todo el mes de junio, cuando muchos visitantes acuden desde Estados Unidos para visitar a San Juan Bautista, patrono municipal. Además de las entrevistas a los emigrantes y los hogares receptores de remesas, se realizaron entrevistas con especialistas en el tema migratorio en Cerritos; con actores responsables del programa de apoyo te son las familias de los emigrantes interrogados en la categoría anterior; no obstante, son los actores responsables del gasto o inversión de los recursos económicos recibidos como producto del trabajo de los familiares residentes en Estados Unidos, y que, en última instancia, inciden en la expresión territorial del proceso que se analiza. Se efectuaron recorridos de superficie para reconocer los sitios en donde se detectaron la inversión y gasto municipal de las remesas obtenidas en cualquiera de sus modalidades y magnitudes, los que se registraron con un GPS.

Los resultados cuantificables obtenidos se categorizaron en grupos de respuestas por intervalos de clase y los cualitativos en categorías representativas similares, y se representaron en mapas con programas especializados de Sistemas de Información Geográfica, ArcView y ArcGis, versión 9.0, y de diseño, Corel Draw, versión 13.0.

\section{Hallazgos investigativos}

\section{Los envíos}

Del total de los emigrantes de Cerritos que fueron entrevistados durante el trabajo de campo, cerca del $75 \%$ envía algún tipo de remesa a los familiares que residen en el municipio. Aunque el monto de los flujos que cada emigrante envía es variable, predominando los montos que oscilan entre 50 y 100 dólares semanales.

Aunado a lo anterior, y a diferencia de antaño (cuando los emigrantes del municipio se desplazaban a Estados Unidos para laborar en el campo), es importante señalar que la cantidad de dinero remitida en la actualidad hacia este sitio depende de las labores que desempeñan los trabajado-

gubernamental conocido como $3 \times 1$; con el párroco de la iglesia de Cerritos, quien tiene contacto con los clubes del municipio que se organizan en Chicago y Houston y quien ofreció información sobre la forma en la que las remesas se emplean para apoyo a la organización de eventos religiosos o el mejoramiento del recinto; también se conversó con integrantes del Club Cerritence Unidos en Chicago. 
res residentes en la Unión Americana; así, el mayor volumen de ingresos proviene de quienes desarrollan actividades en la industria de la construcción, contratistas y mayordomos de haciendas norteamericanas; o bien, existen casos en donde los trabajadores que residen en el extranjero desde hace varios años establecen negocios o adquieren ranchos de los que obtienen beneficios económicos importantes; en conjunto, todas estas actividades les permiten obtener ingresos superiores a 1.000 dólares semanales y, en correspondencia, enviar remesas más cuantiosas (Figura $\mathrm{N}^{\circ} 1$ ).
Entre los emigrantes que residen en Estados Unidos y remiten envíos hacia la familia en el municipio de Cerritos, se identifican dos categorías principales de personas:

1. Quienes contribuyen con sus envíos al gasto de la familia de los padres, pues la mayoría de aquellos reside con su familia nuclear en Estados Unidos.

2. Quienes no envían recursos o lo hacen de forma eventual a familiares más lejanos o la familia no nuclear. Estos envíos exceden con frecuencia los 100 dólares debido a que no tienen familia que sostener y que habite con ellos.

\section{Figura $\mathrm{N}^{\circ} 1$}

Remesas emitidas por migrantes nacidos en Cerritos que residen en Estados Unidos

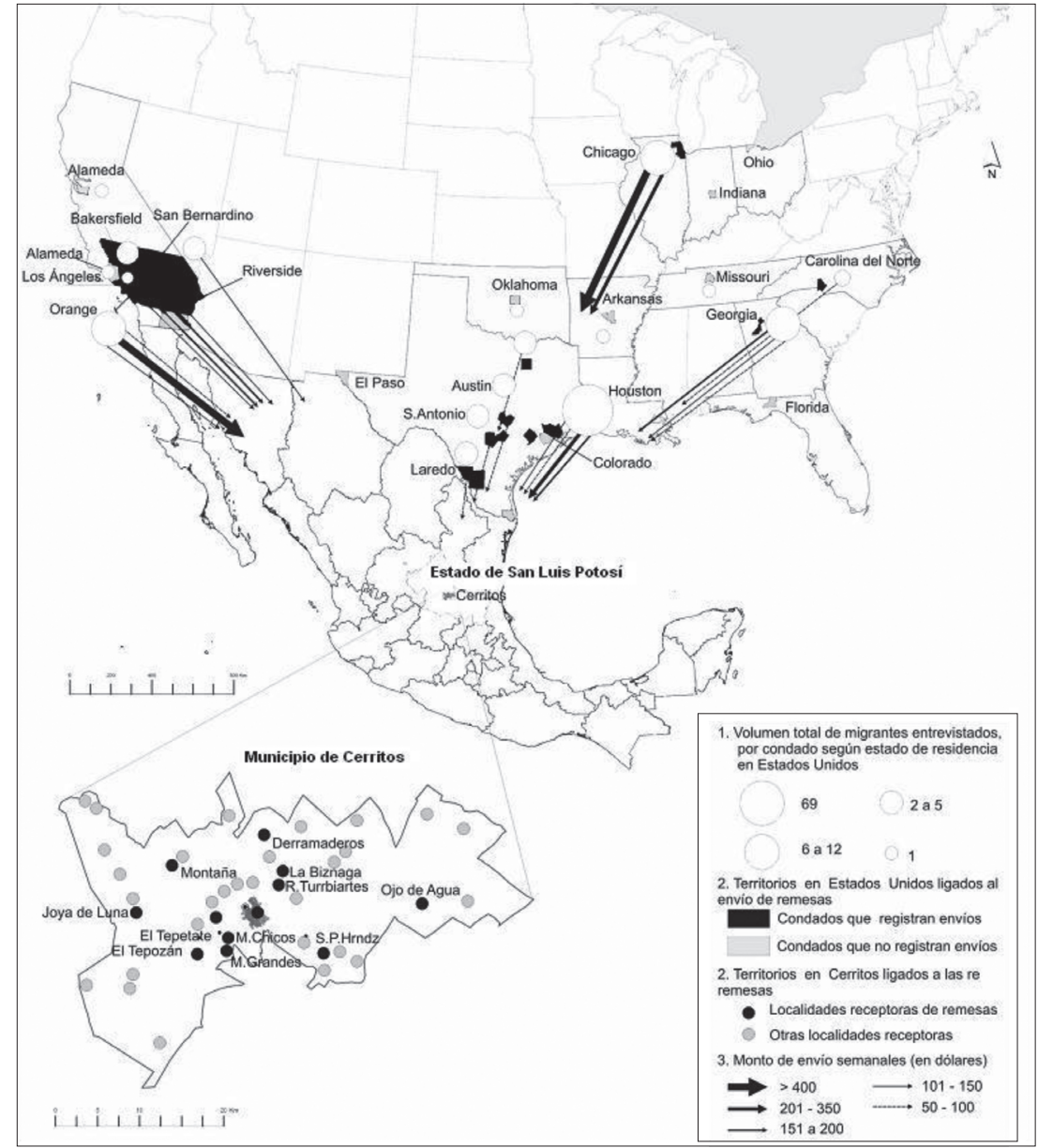

Fuente: Elaboración propia. 
Las estrategias de transferencia de recursos económicos provenientes de las remesas más empleados por las familias receptoras son las casas de cambio y los bancos, en ese orden de preferencia, y una minoría efectúan las transacciones en las áreas de telégrafos o bien en Western Union.

En complemento, aunque se incrementó la transferencia electrónica de remesas monetarias entre 1995 y 2005 con respecto a las de pago o money order por la rapidez con las que se transfieren aquellas (Hernández y Pérez, 2006), los viajes realizados por los trabajadores que regresan al sitio de origen y transportan consigo dinero en efectivo con la consigna de entregarlo a los familiares de quienes lo envían o a través del servicio de carteros, son estrategias recurrentes porque se consideran seguras, facilitan la disposición inmediata de efectivo y se evita el pago de elevadas comisiones.

\section{Estructura territorial generada por modalidades de remesas}

El siguiente apartado identifica el impacto territorial generado por la inversión y el gasto de dinero proveniente de las remesas que envían los emigrantes originarios de Cerritos que residen en Estados Unidos.

De los hogares entrevistados, más del $70 \%$ recibe, además de dinero, remesas no monetarias una o dos veces al año, aunque algunas familias los reciben con una mayor frecuencia y más de la mitad del total de hogares receptores disponen de entre 150 y 200 dólares semanales, aunque alguna minoría recibe incluso hasta 500 dólares. Es frecuente encontrar hogares que reciben apoyo económico de dos o más familiares, quienes se turnan para efectuar los envíos por semana o quincena.

a) Remesas monetarias particulares y familiares

Aunque los usos que se le otorgan son numerosos, incluyen a todos los envíos de dinero que impactan directamente en las economías domésticas y que se destinan principalmente a cubrir los gastos mediante la adquisición de bienes de consumo inmediato, como alimentación, calzado y vestido, servicios asociados a la vivienda (electricidad, agua, combustibles), educación, salud, construcción, ampliación o reacondicionamiento de las viviendas de los emigrantes, quienes con frecuencia tienen predilección por las viviendas estilo americano y la cobertura de gastos derivados de la organización de eventos sociales que refuerzan los lazos familiares y dentro de la comunidad.

El flujo de dinero externo hacia el municipio dinamiza una economía que se orienta en los últimos años al desarrollo de la actividad comercial, al tiempo que genera una accesibilidad diferencial entre las familias que se sostienen del dinero procedente de las remesas y quienes no cuentan con ese apoyo. Con ello, la estructura territorial económica en Cerritos se ha modificado paulatina, pero sensiblemente, de una economía ligada a las actividades primarias hacia el sector terciario, movilizado por el incremento en los flujos de dinero externo hacia la localidad. No obstante, y aunque en menor proporción, las actividades primarias también son objeto de impacto por el ingreso obtenido de las remesas en la medida que el campo se dinamiza mediante la compra de alimento para ganado, semilla mejorada para la obtención de mejores rendimientos agrícolas, si bien no son las prácticas más recurrentes.

El cambio en la orientación sectorial de la economía municipal se percibe de distintas maneras, en la medida que se acelera el desarrollo de la industria de la construcción, se intensifica la venta de materiales para vivienda y la fuerza de trabajo en este sector adquiere mayor demanda. Al mismo tiempo, los terrenos en algunas zonas del municipio adquieren una creciente plusvalía: El Tepozán, Joya de Luna, Derramaderos, La Biznaga, Mezquites Chicos y Mezquites Grandes, El Tepetate, entre otras, y la concentración que impera en la construcción de vivienda en la cabecera municipal. Por lo tanto, es evidente la modificación de los atributos del 
estado geográfico como la expansión urbana que se observa particularmente en algunos barrios como el de San Francisco -que concentra la mayor captación de remesas particulares- y San Juan, en donde además del cambio fisonómico, surgen nuevas colonias con edificaciones tipo americano, una situación por demás recurrente en los barrios de San Antonio, La Santa Cruz y uno de reciente creación llamado Francia (Figura $\mathrm{N}^{\circ} 2$ ).

En correspondencia, el desarrollo de la zona comercial en el centro del municipio, constituye un corredor que anima la vida del municipio y atrae a la población de localidades de otros municipios colindantes.
En conjunto, y aunque las ventajas generadas por lo anterior son evidentes, esta situación ha generado profundos desequilibrios entre la población que depende del ingreso obtenido en dólares y quienes no cuentan con tal recurso. De hecho, se observa un contraste en el incremento del costo de los bienes y servicios en la cabecera municipal, la accesibilidad a servicios de mejor calidad por ubicarse en este sitio geográfico y ventajas adicionales como una mayor cotización de la propiedad y el suelo en donde se ubica, la cercanía a la capital del estado con el consecuente beneficio de servicios de mejor calidad próximos a la cabecera municipal. En contraste, la población que no cuenta con tales ventajas se asocia con problemas

Figura $\mathrm{N}^{\circ} 2$

Manifestación territorial de las remesas en la cabecera municipal de Cerritos

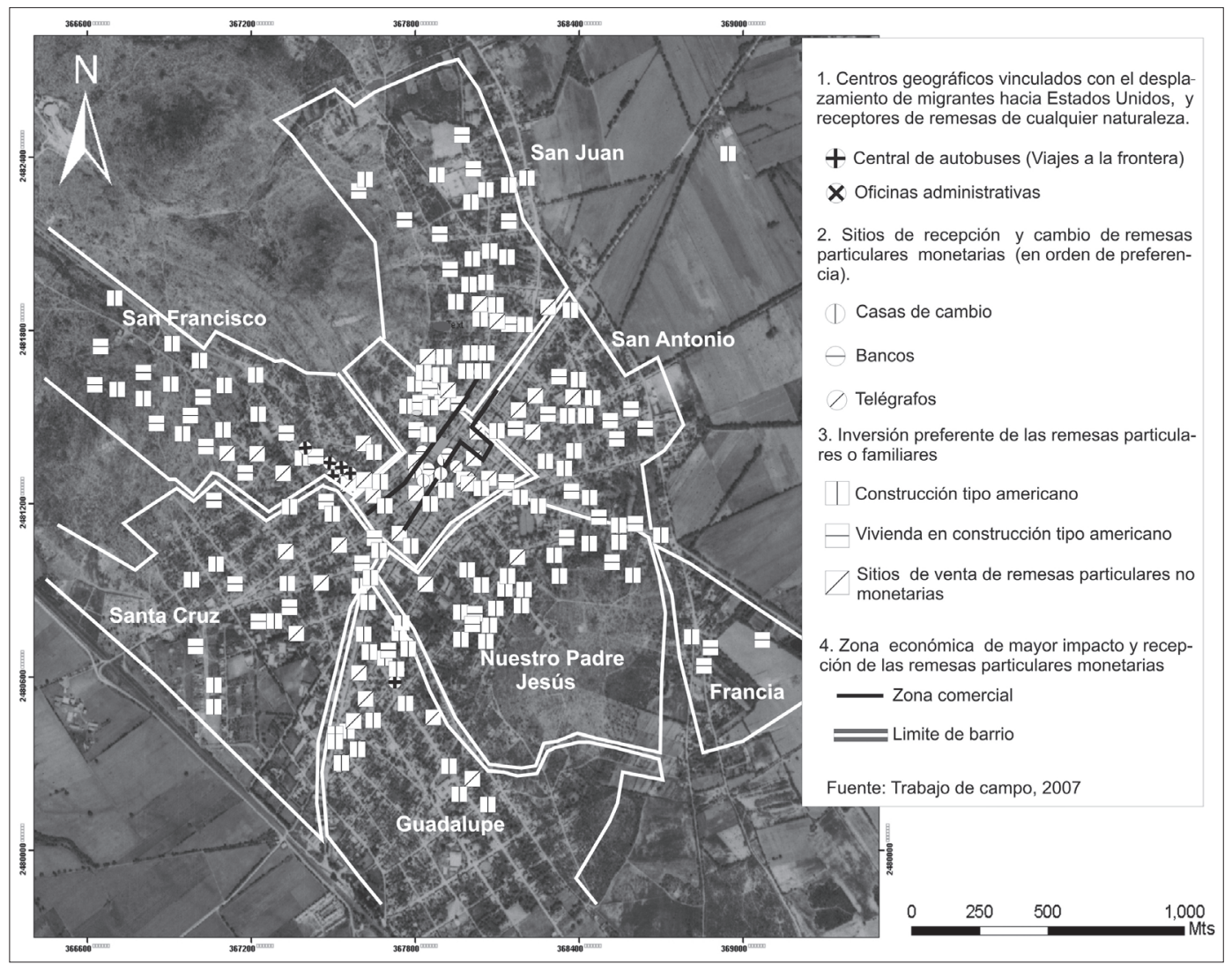

Fuente: Elaboración propia. 
de marginación socioeconómica en algunos estratos sociales.

\section{b) Remesas monetarias colectivas}

En Cerritos, esta modalidad de remesas se distingue como aquellos fondos económicos que recaudan las familias de un grupo de emigrantes mediante la organización de fiestas, kermeses, bailes y otros eventos sociales para crear obras en beneficio de la comunidad de origen. En esta categoría se incluyen los clubes o pequeños grupos de migrantes cuyos ingresos no se registran en el programa de apoyo denominado $3 \times 1^{7}$.

El programa $3 \times 1$ promueve y apoya obras para las comunidades del país, con recursos monetarios
A partir de 2004 las obras realizadas por este programa se intensificaron de forma notoria en algunas comunidades que optaron por participar en él, tales como El Tepetate, Ojo de Agua, El Tepozán, Mezquites Chicos, Mezquites Grandes, Labor de San Diego, Tanquito de Banda, San Pedro de los Hernández, Joya de Luna, La Rinconada, La Biznaga y la cabecera municipal, donde se reportan obras que incluyen el asfaltado de calles, la habilitación de infraestructura eléctrica, la construcción de centros de salud, capillas para cultos religiosos, así como una planta tratadora de agua que se ubica en las inmediaciones de la cabecera munici-

de los migrantes, gobierno federal, estatal y municipal, con una cantidad igual según el presupuesto de la obra. Para 2005, este programa disponía de tan solo 15 millones de dólares y operaba en 23 entidades federativas del país, entre ellas San Luis Potosí.

Figura $\mathrm{N}^{\circ} 3$

Uso de las remesas colectivas para obras en el municipio de Cerritos

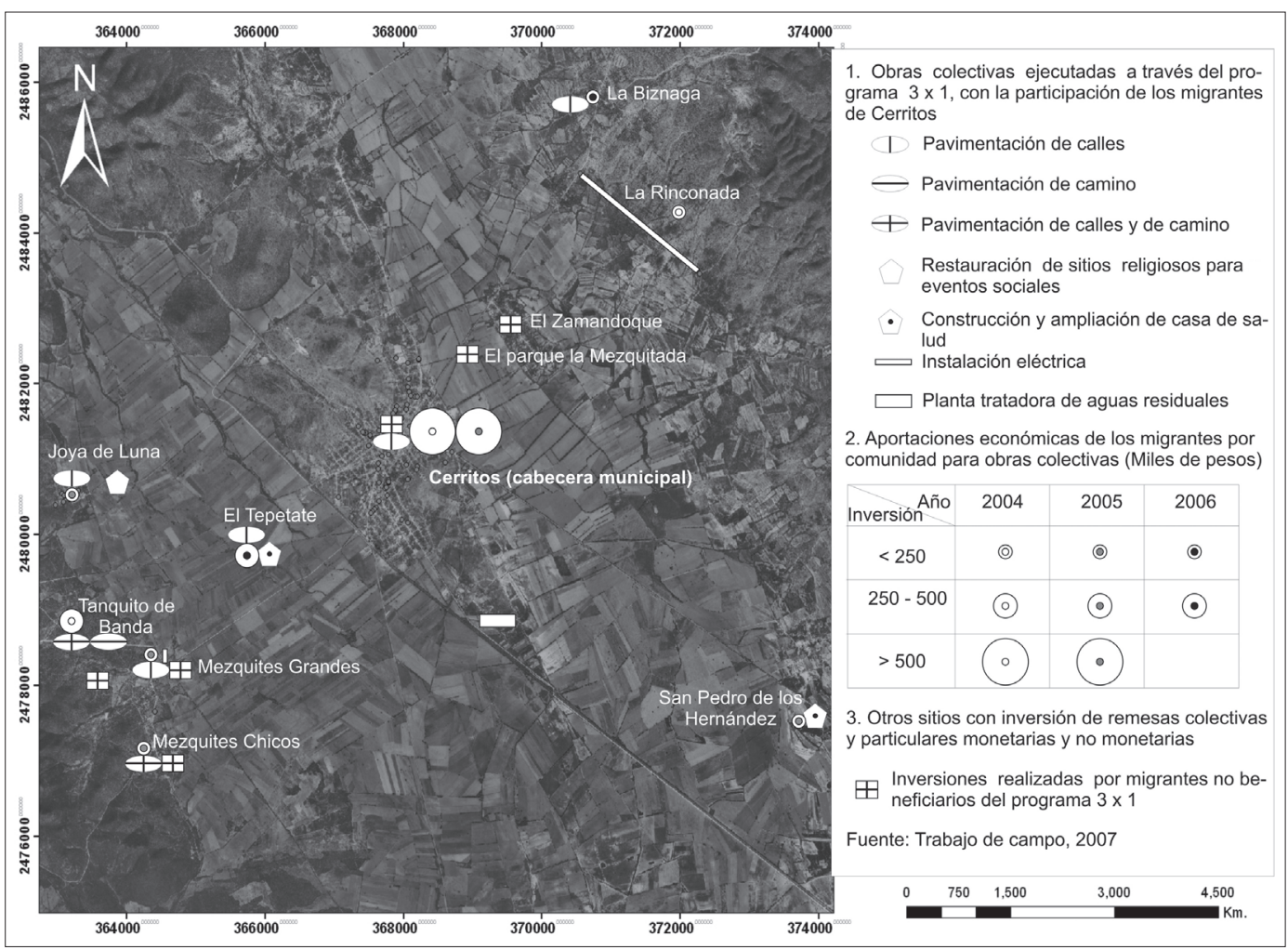

Fuente: Elaboración propia. 
pal, y cuya conclusión se estima para el presente año (Figura $\mathrm{N}^{\circ} 3$ ). Estas obras comunitarias involucran inversiones millonarias que sería muy difícil realizar de no contar con dinero procedente de las remesas enviadas por los trabajadores que residen en Estados Unidos.

También existen otras asociaciones que operan por cuenta propia y recaudan fondos monetarios destinados a obras religiosas, eventos patronales de la comunidad y obras de beneficencia en casas de retiro de personas de la tercera edad, remodelación o compra de equipo inmobiliario para escuelas y becas para estudiantes de educación elemental, entre muchos otros fines.

\section{c) Las remesas no monetarias particulares}

Las remesas no monetarias particulares tienen una ventaja aparente: el dinero tiene mayor liquidez que los envíos de productos en especie para sufragar cualquier necesidad. No obstante, esta última modalidad genera impactos significativos en la sociedad porque quienes los reciben acceden a bienes de consumo inmediato, personal y doméstico, lo que significa un ahorro para el gasto familiar, e incluso son preferidos por algunas personas que las solicitan a los remitentes. De forma paralela, dan lugar a la diversificación de estrategias de sobrevivencia, en la medida que varios hogares que reciben este tipo de apoyos han establecido negocios orientados a la venta de estos productos, bien sea en la zona comercial de la localidad de Cerritos o en su propio domicilio (Figura $\mathrm{N}^{\circ} 3$ ).

Estas remesas son evidentes en el barrio del centro de la cabecera municipal, en el de San Francisco, San Juan y Guadalupe, lugares en donde proliferan los comercios con productos de segunda categoría procedentes de Estados Unidos. Este sistema genera una competencia importante con los comercios de productos nacionales, con una ventaja significativa para los comercios que expenden los productos extranjeros que tienen un costo inferior y una calidad aparente mayor, situación que promueve niveles diferenciales en las ventas que cada tipo de comercio realiza. Ante tal situación, los propietarios de algunos comercios han optado por com- binar productos nacionales y estadounidenses para incrementar el nivel de ventas y sostener sus negocios activos mediante estas estrategias.

\section{d) Las remesas no monetarias colectivas}

Sin duda, los grandes flujos de remesas de esta naturaleza tienen un trasfondo religioso, si bien no es el único motivo. De hecho, la mayoría de estos envíos están conformados por la dotación de materiales e insumos para acondicionar la parroquia de la cabecera municipal durante la temporada en la que se venera al Santo Patrono del lugar. Aun cuando dentro de los envíos categorizados para esta celebración se incluyen remesas monetarias para cubrir los gastos de la fiesta y la donación de dinero que se otorga al templo, este recurso se acompaña por otras donaciones en efectivo que los emigrantes efectúan durante todo el año y que se opera a través de un fondo destinado para tal fin.

En general, para movilizar las remesas los carteros se dedican al transporte de materiales, herramientas para el trabajo comunitario en el campo, en la industria de la construcción, y son reconocidos por la población como los distribuidores de paquetería en especie. Los sitios geográficos receptores de estas remesas coinciden en lo general con los receptores de las remesas monetarias colectivas, pero la cabecera municipal y comunidades como El Tepozán, entre otras, son las principales localidades depositarias de estos envíos, principalmente en las temporadas de fiestas patronales.

\section{Consideraciones finales}

Tras haber analizado el proceso migratorio y la incidencia en la estructura territorial que la economía de las remesas genera en el municipio examinado, se resalta lo siguiente:

En años recientes, la estructura económica del territorio de Cerritos evidencia cambios notorios a medida que crecen los recursos económicos remitidos por un creciente contingente de población local que reside en Estados Unidos y constituye un proceso secular que se inició hace poco más de un siglo pero recientemente ha motivado una 
sinergia indisoluble en el lugar. Los patrones observados en la dinámica económica municipal evidencian que el dinero de las remesas tiene un doble propósito; por una parte se destina a cubrir los gastos de la población receptora municipal mediante la adquisición de bienes de consumo inmediato $y$, al mismo tiempo, se invierte en infraestructura y obras de beneficio colectivas que, con frecuencia, le corresponde ejecutar al gobierno, pero no siempre es capaz de realizarlas o no forman parte prioritaria de sus estrategias de desarrollo socioeconómico.

En este contexto, los flujos de dinero y en especie se manifiestan en un rápido crecimiento de infraestructura de apoyo y el empleo que incentivan actividades productivas como la agricultura comercial y la ganadería, pero sobre todo en el aumento desproporcional del comercio y los servicios en ciertos espacios, así como la terciarización de la población económicamente activa que reside en Cerritos, especialmente en la cabecera municipal.

No obstante, la aparente bonanza económica de una economía dolarizada se acompaña por la manifestación de profundas desproporciones sociales, que polarizan diferencias entre la población que cuenta con dinero procedente de las remesas y quienes no cuentan con dicha posibilidad. Ante ello, la centralización de los medios de producción, del dinero y de la vida económica local significa una estrategia de sobrevivencia efectiva para un sector de la población, de manera similar a como se expresan en el espacio geográfico tales diferencias estructurales. Al mismo tiempo, la modificación de los atributos característicos del anterior paisaje rural que caracterizaba a las localidades de Cerritos hacia el surgimiento de barrios con una fisonomía extranjera, es el resultado de nuevas tendencias de asimilación cultural, de culturas heterogéneas y contrastantes que se aprecian en el tipo de vivienda, los productos que ofrecen los comercios y en la infraestructura existente $y$ que fueron construidos $u$ ofertados con dinero nacional y los que se hacen con dinero de remesas.

El estudio de la temática migratoria en el municipio de Cerritos es de utilidad y perti- nencia para que las instancias gubernamentales que toman las decisiones supremas en el ámbito local, municipal y regional, reconozcan el origen y los procesos asociados con la variable migratoria. Así, contarán con argumentos validados para generar e instrumentar los planes y programas de desarrollo y apoyo estatal y municipal en materia social.

Concretamente, y en virtud del diagnóstico de la problemática detectada en esta investigación, es conveniente incentivar la inversión de las remesas monetarias colectivas y particulares en obras e infraestructura de apoyo para el sector primario en la medida que generará un impacto positivo en dos niveles: primero, incrementará la generación de empleos a través de la demanda de fuerza de trabajo requerida para crearlas y, segundo, incrementará el nivel de productividad de la agricultura comercial, una de las modalidades con amplia tradición en el lugar. Esta situación significa una ventaja competitiva para Cerritos si se compara con las condiciones que imperan en la agricultura típica de los demás municipios de la región.

En síntesis, al incrementar el volumen de inversión de los recursos foráneos obtenidos, se reactivará la economía primaria y se establecerá una participación equilibrada entre los sectores productivos a mediano y largo plazo. Además, el fomento de proyectos de desarrollo rural, significa una alternativa no solo viable, sino necesaria para las economías domésticas receptoras de remesas, pues ante la reciente crisis financiera acontecida en Estados Unidos de América y propagada en el ámbito internacional, la movilización de trabajadores de México hacia Estados Unidos y aun del municipio de Cerritos, ha comenzado a revertirse, con la consecuente reducción en el flujo de dinero recibido por ese concepto.

\section{Referencias bibliográficas}

ALANIS, F. La contratación de Braceros en San Luis Potosí y el Gobierno del Estado (1944). En: ENCISO, S. A. (Coord.) La emigración de San Luis Potosí a Estados Unidos pasado y presente. Monterrey: Colegio de San Luis y Senado de la República, 2001, p. 33-70. 
ALANÍS, F. Regreso a casa: la repatriación de mexicanos en Estados Unidos durante la gran depresión. El caso de San Luis Potosí, 1929-1934. Estudios de historia moderna y contemporánea de México, 2005, № 29. Disponible en Internet: www.ejournal.unam.mx/ ehm/ehm29/EHM000002904.pdf

ARANGO, J. La explicación teórica de las migraciones: luz y sombra. Migración y Desarrollo, 2003, $\mathrm{N}^{\circ} 1$. Disponible en Internet: http://meme.phpwebhosting.com/ migracion/modules/ve1/JoaquinArango.pdf

ARAGONÉS, A. et al. Nuevos determinantes para la migración en la relación México-Estados Unidos. Un acercamiento teórico. En: San Cristóbal de Las Casas, X Congreso internacional sobre integración regional, fronteras y globalización en el continente americano, 2006.

BARROS, A. La migración en la economía internacional. ISIRI Boletín electrónico, 2005, No 8. Disponible en Internet: http:// www.isri.cu/Paginas/Boletin/bolet_int.htm

CASTLES, S. y MILLER, J. La era de la migración. Movimientos internacionales de población en el mundo entero. Ciudad de México: Coeditado por la Universidad Autónoma de Zacatecas, Secretaría de Gobernación, H. Cámara de Diputados LIX Legislatura, Instituto Nacional de Migración, Fundación Colosio, Miguel Ángel Porrúa, 2004.

DELGADO, R. y MAÑÁN, O. Migración México-Estados Unidos e integración económica. Política y Cultura Primavera, 2005, No 23, p. 9-23.

DURAND, J. La migración mexicana a los Estados Unidos en los años veinte: una antología. Ciudad de México: Consejo Nacional para la Cultura y las Artes, 1991.

DURAND, J. Más allá de la línea. Patrones migratorios entre México y Estados Unidos. Ciudad de México: Editorial Consejo Nacional para la Cultura y las Artes, 1994.

DURAND, J. y MASSEY, D. Clandestinos migración México-Estados Unidos en los albores del siglo XXI. Ciudad de México: Uni- versidad Autónoma de Zacatecas, Miguel Ángel Porrúa, 2003.

FERNÁNDEZ, R. Migraciones y remesas en el contexto de la globalización. En: Okinawa, 46 reunión de la Junta de Gobernadores del Banco Inter-Americano de Desarrollo y de la Corporación Inter-Americana de Inversiones, Fondo de Población de las Naciones Unidas, 6 de abril de 2005. Disponible en Internet: http://idbdocs.iadb.org/ wsdocs/getdocument.aspx? docnum $=556470$

GIUSTI, A. Trayectorias migratorias, redes de intercambio y circulación en la comunidad chilena en Argentina. En: Tours, XXV Conferencia internacional de población, 2005. Disponible en Internet: http:// iussp2005.princeton.edu/dowload.aspx

GONZÁLEZ, L. Siete etapas de la migración México-Estados Unidos. En: OCHOA SERRANO, Á. (Coord.) "... Y nos volvemos a encontrar". Ciudad de México: Colegio de Michoacán y Centro de Investigación y Desarrollo del Estado de Michoacán, 2001, p. 15-20.

HERNÁNDEZ, E. y PÉREZ, F. El impacto de las remesas familiares sobre el nivel de precios y el tipo de cambio a nivel nacional (1994-2004). En: San Cristóbal de Las Casas, X Congreso internacional sobre integración regional, fronteras y globalización en el continente americano, 2006.

HERRERA, F. y MACÍAS, S. Migración de la mixteca poblana a Nueva York: espacio social trasnacional. En: MACÍAS, S. y HERRERA, F. (Coord). Migración laboral internacional. Puebla: Benemérita Universidad Autónoma de Puebla, 1997, p. 107-164.

LACOMBA, J. Teorías y prácticas de la inmigración. De los modelos explicativos a los relatos y proyectos migratorios. Scripta Nova. Revista electrónica de Geografía y Ciencias Sociales, 2001, No 94. Disponible en Internet: http://www.ub.es/geocrit/sn-943.htm

LOZANO, F. Experiencias Internacionales en el envío y uso de remesas. En: TURIÁN, R. (Coord). Migración México-Estados Unidos. Opciones de política, Ciudad de 
México: Consejo Nacional de Población, 2000, p. 147-166.

MONROY, M. I. Rastros de una emigración antigua. En: ALANIS, E. y FERNANDO, S. (Coord). La emigración de San Luis Potosí a Estados Unidos pasado y presente. Monterrey: Colegio de San Luis y Senado de la República, 2001, p. 14-40.

MONTOYA, R. La experiencia potosina en Chicago. San Luis Potosí: Colegio de San Luis, 1997.

MONTOYA, R. La migración potosina hacia los Estados Unidos de norteamérica antes y durante el programa Bracero. El caso de Cerritos, San Luis Potosí, San Luis Potosí. Ciudad de México: Ponciano Arriaga, 2006.

PÉREZ, M. El trabajo como vida y como idea: la migración laboral internacional en una comunidad de Michoacán. En: PATIÑO, T. y CASTILLO, J. (Compiladores). Trabajo y Migración. Ciudad de México: $2^{\circ}$ Congreso RNIU (Investigación Urbana y Regional), 2001.

PIORE, M. Bird of passage. Migrant labor and industrial societies. New York: Cambridge, University Press, 1979.

ROCHA, J. ¿Por qué se van? La onda migratoria y las teorías que la explican. Revista
Envío, 2003, no 256. Disponible en Internet: http://www.envio.org.ni/articulo/1241.

RODRíGUEZ, I. México, campeón de la migración; 11 millones de expulsados a EU. La Jornada, 13 de febrero de 2007. Disponible en Internet: http://www.jornada. unam.mx/2007/02/13/index.php?section $=$ economia \&article $=024 \mathrm{n} 1 \mathrm{eco}$

VELEDA, S. Desplazamientos y relación con los lugares: un estudio cualitativo. Scripta Nova. Revista electrónica de Geografía y Ciencias Sociales, 2001, No 94. Disponible en Internet: http://www.ub.es/geocrit/sn-94-102.htm

VERDUZCO, G. La migración mexicana a Estados Unidos: estructuración de una selectividad histórica. En: TUIRÁN, R. (Coord.). Migración México-Estados Unidos presente y futuro, Ciudad de México: Consejo Nacional de Población, 2000, p. 12-30.

VILLEGAS, J. Cerritos en mi recuerdo. Datos históricos del municipio de Cerritos, S.L.P. México. San Luis Potosí: Archivo Histórico del Estado de San Luis Potosí, 2005.

ZÚÑIGA, E. et al. Migración México-Estados Unidos: panorama regional y estatal. Ciudad de México: Consejo Nacional de Población y la Secretaría de Gobernación, 2005. 